\title{
Effect of Ultraviolet C Irradiation on Isoflavone Concentrations in Different Cultivars of Soybean (Glycine max)
}

\author{
Krishna Bahadur Karki ${ }^{1,+}$, Awdhesh Kumar Mishra ${ }^{2,+}+$, Seong-Jin Choi ${ }^{3}$ \\ and Kwang-Hyun Baek ${ }^{2, *}$ \\ 1 Research and Development Society, Kathmandu 4179, Nepal; kkarki2000@gmail.com \\ 2 Department of Biotechnology, Yeungnam University, Gyeongsan, Gyeongbuk 38541, Korea; \\ awadhesh.biotech07@gmail.com \\ 3 Department of Biotechnology, Catholic University of Daegu, Gyeongsan 38430, Korea; sjchoi@cu.ac.kr \\ * Correspondence: khbaek@ynu.ac.kr; Tel.: +82-53-810-3029; Fax: +82-53-810-4769 \\ + These authors contributed equally to this work.
}

Received: 27 July 2020; Accepted: 13 August 2020; Published: 16 August 2020

\begin{abstract}
Phytoestrogens are naturally occurring plant polyphenolic compounds present in high concentrations in soybean products. Phytoestrogens are divided into three classes: lignans, isoflavones, and coumestans. Nine types of glycoside isoflavones and three types of aglycoside isoflavones are reported in soybean. Soy isoflavones can reduce the risk of a certain type of cancer, cardiovascular problems, osteoporosis, and menopausal symptoms. We irradiated the leaves of five cultivars of soybean with UV-C $(260 \mathrm{~nm})$ and determined the effect on concentrations of isoflavone compounds using liquid chromatography-mass spectrometry (LC-MS). Isoflavone concentrations were significantly higher following irradiation, particularly in the cultivar Daepung, which was selected as the best cultivar for high isoflavone induction with UV-C irradiation. Further experimentation with the cultivar Daepung revealed that 20 min UV-C irradiation was the best treatment for the induction of aglycone compounds, and $5 \mathrm{~min}$ with the dorsal surface facing the UV-C irradiation source was the best treatment for the induction of glycoside isoflavone compounds.
\end{abstract}

Keywords: Glycine max; UV-C; phytoestrogen; isoflavone; induction; irradiation

\section{Introduction}

The solar ultraviolet (UV) spectrum is a continuous spectrum of light that can be divided into three wavelength bands: UV-A (320-400 nm), UV-B (280-320 nm), and UV-C (200-280 nm). The negative effect of UV radiation for living organisms increases as wavelengths shorten. UV-A has a less detrimental effect and plays a significant role in plant photomorphogenesis. UV-B radiation is potentially harmful to living organisms and absorbed to some extent by the atmospheric ozone layer, which reduces its ability to reach the earth's surface. UV-C radiation, which has a shorter wavelength, causes numerous injuries. It is often described as "germicidal UV" due to its ability to deactivate the DNA of a broad range of microorganisms [1]. The dose, which is computed as the multiplication of the intensity (Wm-2) and time of exposure (seconds), is expressed as radiant exposure (Jm-2). UV-C irradiation is well documented for its effect on plants, and light-emitting diodes have been used for this purpose [2-4]. A low dose of UV-C may activate acclimation responses in plants, including the activation of enzymatic and non-enzymatic defense systems [5-8]. High doses of UV-C radiation lead to an overproduction of reactive oxygen species (ROS) that results in oxidative stress, decreased cell viability, and cell death [9-14]. Application of low UV-C doses have been considered for 
commercial purposes as they can prevent pathogenic diseases and delay senescence during fruit and vegetable storage $[15,16]$. However, exposure to ultraviolet radiation can cause various alterations in plant metabolism and affect its biochemical activities [17-19].

Metabolites are compounds synthesized by plants for a specific function. Metabolites involved in growth and development are known as primary metabolites. Secondary metabolites are present incidentally, since they are not essential for plant life [20]. Although secondary metabolites are not essential for survival, they are involved in protection, competition, and species interactions. Secondary metabolites are specific to individual species [21]. Phytoestrogens are naturally occurring plant phenolic, non-steroidal compounds, which are classified as isoflavones, coumestans, and lignans. These compounds are present in high amounts in soy products (e.g., beans and tofu); plant lignans are found in legume grains, seeds, and vegetables [22]. Phytoestrogens are heterocyclic phenolic compounds with a structure similar to that of estrogenic steroids (mammalian endogenous estrogens). Therefore, these compounds show estrogen-like activity or weak antiestrogen-like properties [23]. Isoflavones show clear estrogenic activity, and these compounds are effective for estrogenic therapy $[24,25]$. In addition to isoflavonoids, flavonoids also exert estrogenic effects, but usually at considerably lower levels than those of isoflavonoids [26]. Moreover, some flavonoids, including kaempferol and quercetin, exhibit antiestrogenic activity [27], and several legumes are a source of these flavonoids [28,29].

There are 12 isoflavone compounds in soybean (Glycine max) seeds including 9 types of glycosides (daidzin, malonyldaidzin, acetyldaidzin, glycitin, malonylglycitin, acetylglycitin, genistin, malonylgenistin, and acetylgenistin) and 3 types of aglycones (daidzein, genistein, and glycitein) (Figure 1) [25,30,31]. Other isoflavones are also present in legumes, such as biochanin-A and formononetin [32]. Genistein and daidzein are the predominant and most commonly investigated isoflavones in human nutrition. They can be obtained from soybeans and other legumes including peas, lentils, and beans [33,34]. Generally, soybean plants produce isoflavone compounds in response to environmental stresses. The plants produce different types of isoflavones for defense purposes, and some isoflavones function as antibiotics and antifungal compounds. In addition, some isoflavones play a vital role in cell regulation [35]. Soybeans consist of about two grams of isoflavones per kilogram of fresh weight [36].

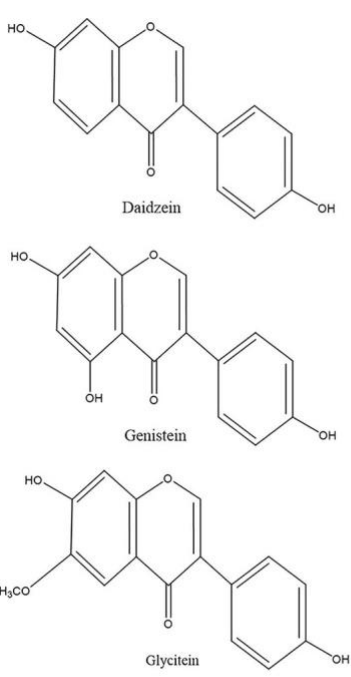

Aglycones
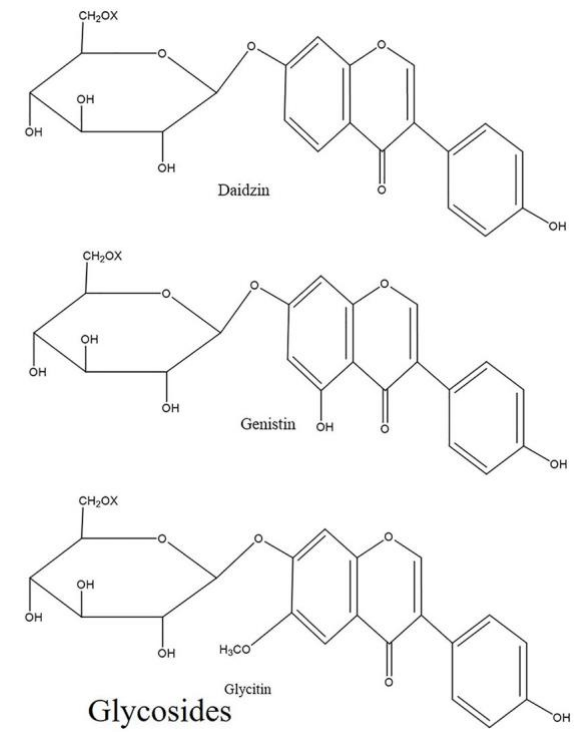

Figure 1. Chemical structure of soybean isoflavones. In soybeans, isoflavones are present in two isoforms: aglycones and glycosides. Release of the sugar moiety from glycosides often generates aglycones. Glycosides have three chemical isoforms: $\beta$-glucoside, acetylglucoside, and malonyl glucoside ( $\mathrm{X}$ represents $\mathrm{H}, \mathrm{COCH}_{3}$, and $\mathrm{COCH}{ }_{2} \mathrm{COOH}$ in $\beta$-glucoside, acetylglucoside and malonylglucoside, respectively). Chemical structures were drawn using ChemDraw Standard 13.0 software (PerkinElmer, Waltham, MA, USA). 
Legumes are present in almost every diet worldwide. Seeds, as well as many other parts of the plant, are also edible. Among legumes, soybeans are an important source of isoflavones, containing high concentrations of daidzein and genistein [32,37,38]. Daidzein and genistein are responsible for many of the health benefits of soy $[39,40]$. The amount of soy isoflavone in diets worldwide has increased because it is associated with a reduced risk of certain types of cancers, cardiovascular problems, osteoporosis, and menopausal symptoms [24,41-44]. In the present study, the leaves of five soybean cultivars were irradiated with UV-C $(260 \mathrm{~nm})$ and their effect on the concentrations of isoflavones was determined. Isoflavone compounds were extracted from the leaves and quantified using liquid chromatography-mass spectrometry (LC-MS).

\section{Results}

\subsection{Effect of $U V-C$ on Isoflavone Concentrations in Different Cultivars of Soybean}

UV-C irradiation of soybean leaves has been associated with higher concentrations of isoflavone compounds. Nine isoflavone compounds, namely, daidzin, malonyldaidzin, and daidzein at mass-to-charge ratio: $\mathrm{m} / \mathrm{z} 255$; genistin, malonylgenistin, and genistein at $\mathrm{m} / \mathrm{z} 271$; and glycitin, malonylglycitin, and glycitein at $m / z 285$ were identified by LC-MS analysis. The concentrations of different isoflavonoid compounds and total isoflavone in the leaves of five cultivars of G. max after UV-C treatment are shown in Table S1 and Figure 2.

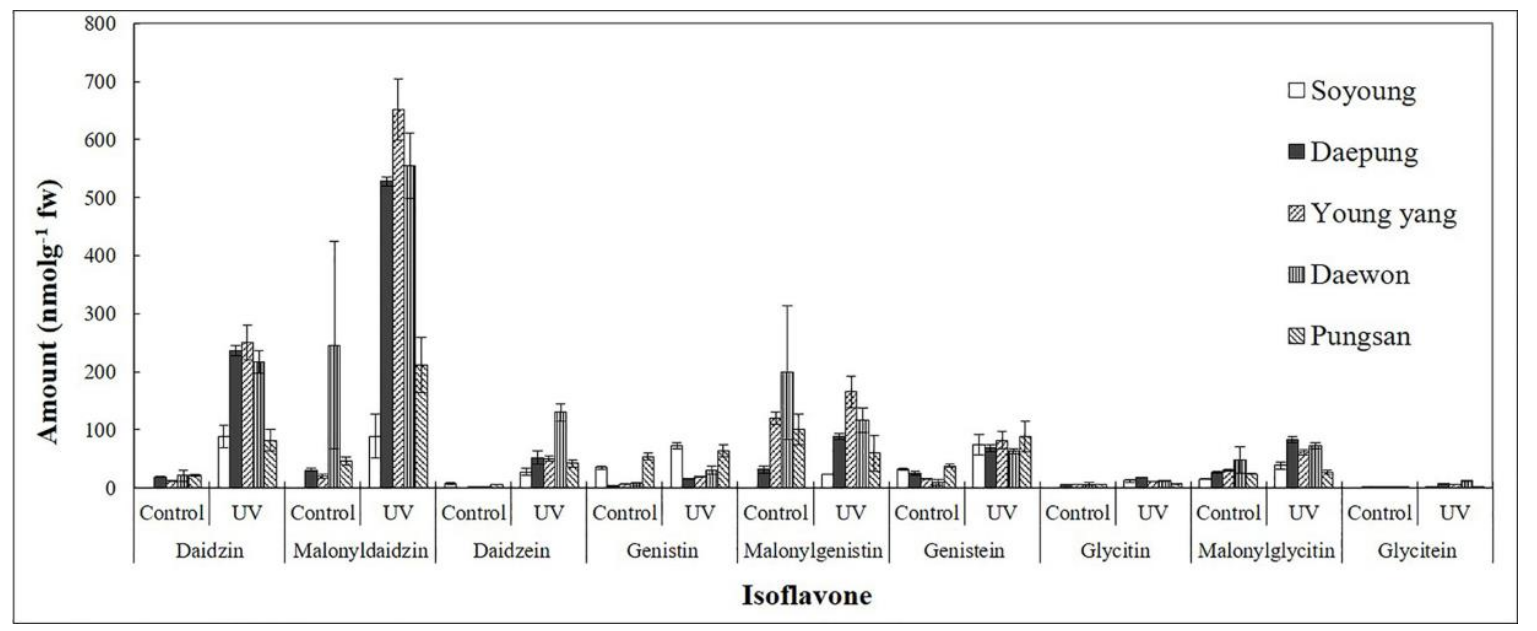

Figure 2. Isoflavone concentrations in five different cultivars of soybean leaves after 5 min UV-C treatment. The $x$-axis represents the different isoflavone compounds in five different cultivars and the $y$-axis represents the concentration of isoflavone compounds (unit: $\mathrm{nmol} \mathrm{g}^{-1}$ of fresh weight). The error bars represent the means \pm standard deviation $(n=3)$.

The total isoflavone concentrations were also higher after 5 min UV-C treatment compared with the controls. The total isoflavone concentrations after UV-C treatment were 1094 and $1296.57 \mathrm{nmol} \mathrm{g}^{-1}$ of fresh weight in the cultivars Daepung and Young-yang, respectively (Table S1, Figure 3). Compared with the control (without UV-C irradiation), isoflavone concentration in irradiated leaves was 7.72- and 6.18-fold higher in the cultivars Daepung and Young-yang, respectively. We observed a large variation in isoflavone concentration among the different cultivars. Hence, selection of cultivars is a significant parameter for optimizing the isoflavone concentration in soybean [45].

Aglycone compounds were observed in different cultivars of soybean after 5 min irradiation. The concentrations of daidzein and glycitein were 130.21 and $11.73 \mathrm{nmol} \mathrm{g}^{-1}$ of fresh weight, respectively, in the cultivar Daewon. Similarly, genistein concentration was $81.88 \mathrm{nmol} \mathrm{g}^{-1}$ of fresh weight in the cultivar Young-yang (details are given in Table S1). 


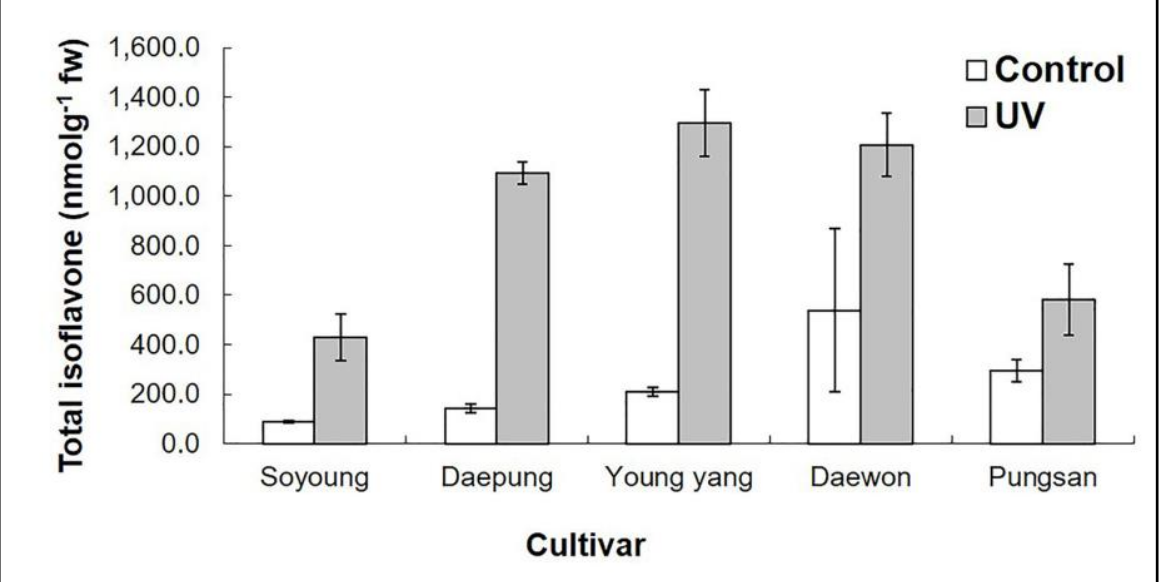

Figure 3. Total isoflavone concentration in different cultivars after 5 min UV-C treatment. The $x$-axis represents the different cultivars of soybean, whereas the $y$-axis represents the total isoflavone concentration (unit: $\mathrm{nmol} \mathrm{g}^{-1}$ of fresh weight). The error bars represent the means \pm standard deviation $(n=3)$. Means with the same letter are not significantly different $(p \leq 0.05)$.

\subsection{Effect of UV-C on Isoflavone Concentration in G. max cv. Daepung}

After determining the most effective cultivar for total isoflavone induction under UV-C irradiation, we investigated the appropriate time period for UV-C irradiation. The UV-C treatment of soybean leaves was conducted for different lengths of time with the cultivar Daepung, and isoflavone concentration was estimated using LC-MS (Table S2 and Figure 4). The highest total isoflavone concentration, $5430 \mathrm{nmol} \mathrm{g}^{-1}$ of fresh weight, was observed in the treatment where the adaxial (upper) surface was facing the UV-C source for $5 \mathrm{~min}$ (Figure 4). This treatment resulted in a 7.75-fold higher total isoflavone concentration than that in the control.

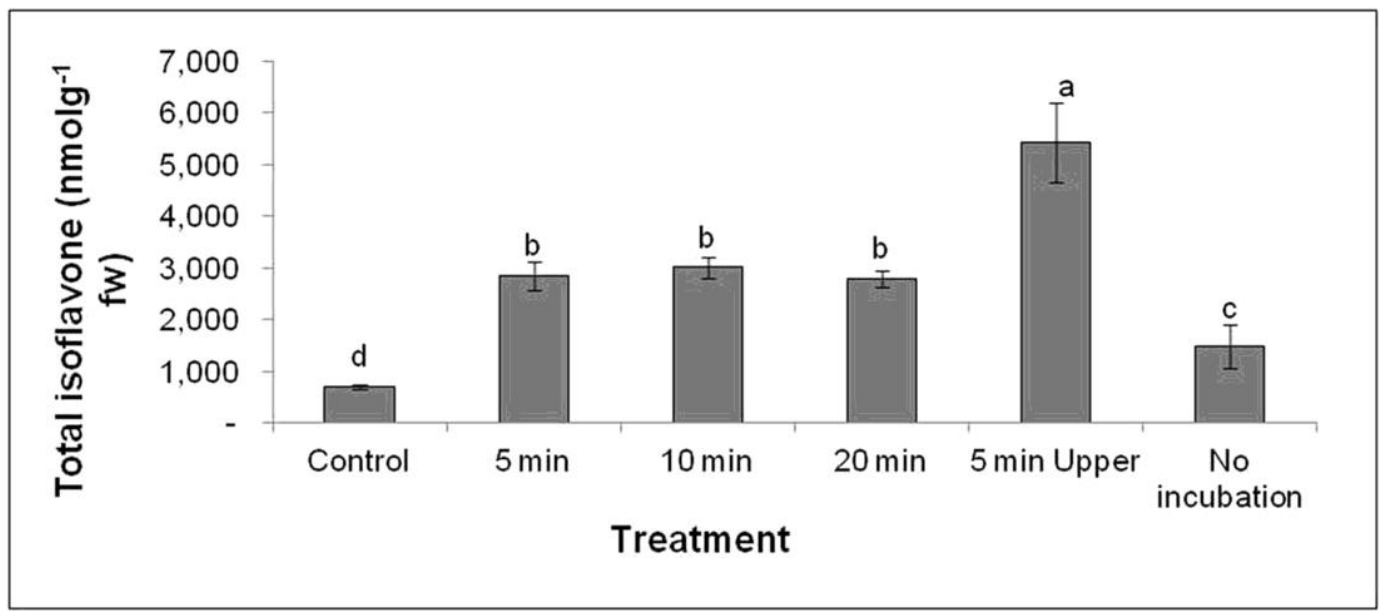

Figure 4. Total isoflavone concentration in Glycine max cv. Daepung after UV-C treatment for different time periods (unit: $\mathrm{nmol} \mathrm{g}^{-1}$ of fresh weight). Here, leaves without UV-C irradiation and incubated in the dark are considered as the control. The leaves without UV-C irradiation as well as without incubation are indicated as "no incubation". The leaves in which adaxial (upper) surface facing the UV light source, is termed as " 5 min Upper". The error bars represent the means \pm standard deviation $(n=3)$. Means with the same letter are not significantly different $(p \leq 0.05)$.

The highest concentrations of the glycoside compounds daidzin, malonyldaidzin, genistin, malonylgenistin, glycitin, and malonylglycitin were $984.3,2572,397.3,981.7,39.1$, and $307.3 \mathrm{nmol} \mathrm{g}^{-1}$ of fresh weight, respectively, and these were observed after the adaxial (upper) surface was facing the 
UV-C source for $5 \mathrm{~min}$ (Table S2). Conversely, the highest concentrations of the aglycone compounds daidzein, genistein, and glycitein were $557.9,233.3$, and $37.9 \mathrm{nmol} \mathrm{g}^{-1}$ of fresh weight, respectively, and these were observed after $20 \mathrm{~min}$ UV-C treatment (Table S2, Figure 5). The approximate fold increases in aglycone compound concentration (as compared to that of the control) for each treatment are presented in Figure 6.
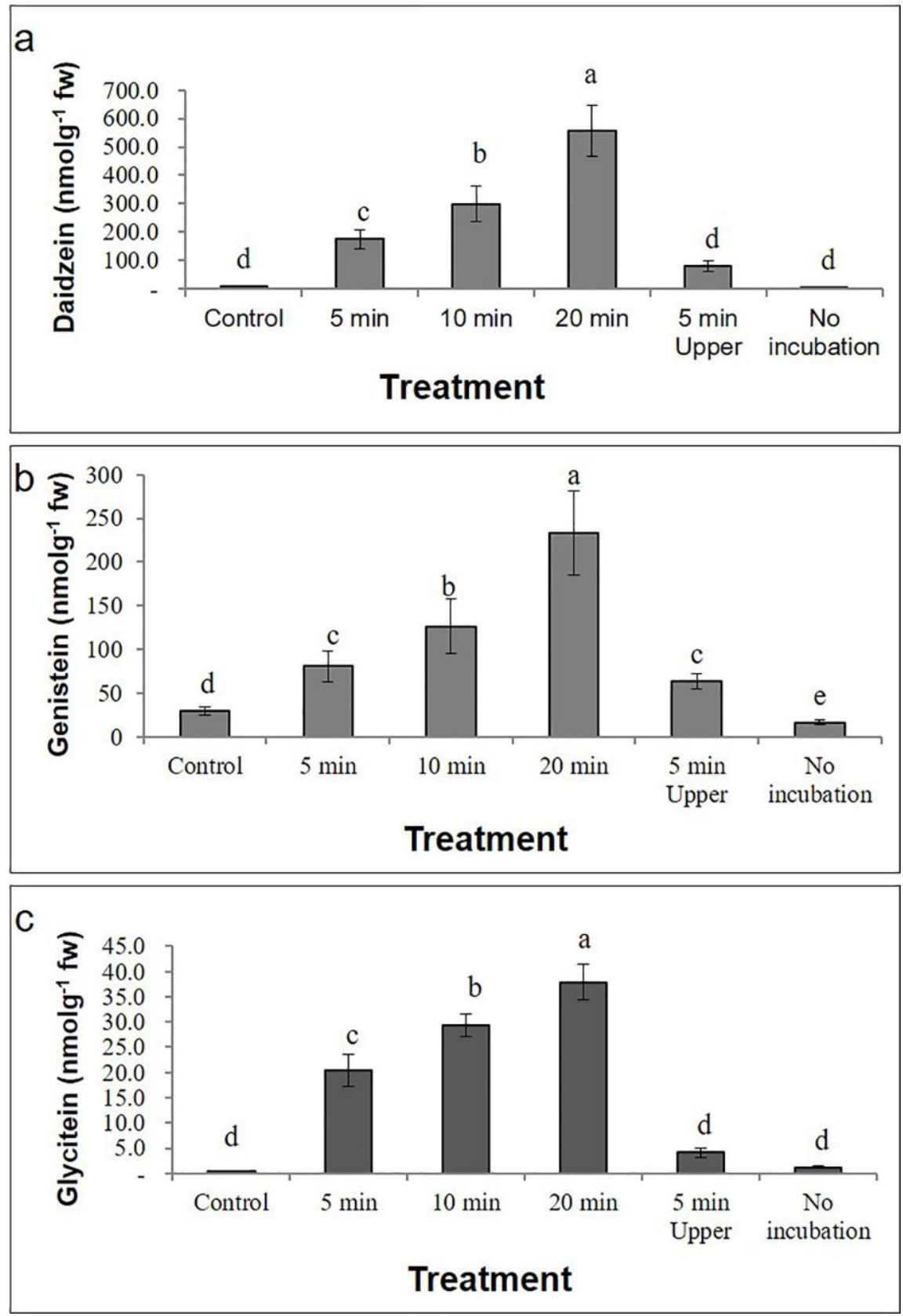

Figure 5. Concentrations of the aglycone compounds (a) daidzein, (b) genistein, and (c) glycitein in G. $\max \mathrm{cv}$. Daepung after UV-C irradiation for different time periods (unit: $\mathrm{nmol} \mathrm{g}^{-1}$ of fresh weight). The treatment without UV-C irradiation and without incubation is indicated as "no incubation". The error bars represent the means \pm standard deviation $(n=3)$. Means with the same letter are not significantly different $(p \leq 0.05)$. 


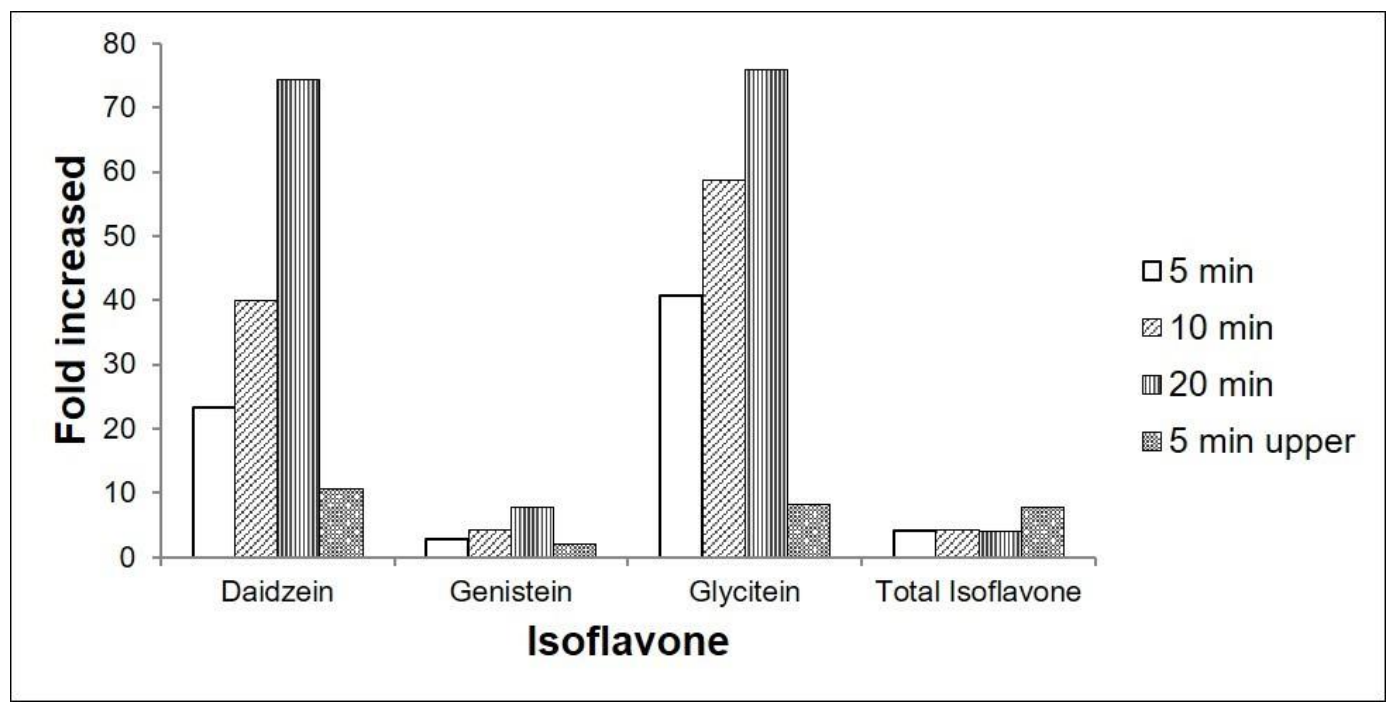

Figure 6. Approximate fold increase in aglycone compounds (daidzein, genistein, and glycitein) and total isoflavone concentration in G. max cv. Daepung after UV-C irradiation. Bars represent the fold increase after UV-C treatment for different time periods compared to that of the control.

\section{Discussion}

Isoflavones are phytochemicals present in legumes and are predominately found in soybean. Soybean plants contain a relatively high amount of isoflavone compounds compared with other plants. Since they are a rich source isoflavones, they are often included in the human diet [46]. Given that abiotic and biotic stresses can increase the concentrations of many metabolic compounds in plants, it is possible that this can also be the case for isoflavones in soybean plants [2,47-51]. Therefore, we investigated the low dose of UV-C could act as an elicitor for the induction of isoflavones in soybean plants. We estimated the concentrations of nine isoflavones (six glucosides and three aglycones) under various doses of UV-C irradiation.

After 5 min UV-C irradiation, the total isoflavone concentrations in cultivars Daepung and Young-yang were 7.72- and 6.18-fold higher, respectively, than those in the control. After irradiation, the malonyldaidzin concentration in the cultivar Young-yang was 33.41-fold higher than that in the control (Figure 3, Table S1). After 5 min UV-C treatment, the highest concentrations of malonyldaidzin and malonylgenistin (651.91 and $165.05 \mathrm{nmol} \mathrm{g}^{-1}$ of fresh weight, respectively) were observed in the cultivar Young-yang, and the highest concentration of malonylglycitin $\left(83.18 \mathrm{nmol} \mathrm{g}^{-1}\right.$ of fresh weight) was observed in the cultivar Daepung. The concentrations of malonyl glucosides, a major form of glucosides, increased in response to $5 \mathrm{~min}$ UV-C irradiation. Malonyl glucosides are thermally unstable and convert into their corresponding glycosides [30,52]. Previously, it has been reported that $1 \mathrm{mM}$ and $100 \mu \mathrm{M}$ salicylic acid applied at the blooming stage of soybean increased malonyldaidzin concentration by $18 \%$ and $15.5 \%$, respectively [53]. In a previous study, genistin, genistein, daidzein, and biochanin-A concentrations were increased significantly after UV irradiation in callus cultures of Genista tinctoria. Genistin concentration increased by approximately 3\% after $5 \mathrm{~min}$ UV $254 \mathrm{~nm}$ radiation and by $2 \%$ after $2 \mathrm{~min} U \mathrm{UV} 366 \mathrm{~nm}$ radiation [53].

In general, the concentrations of aglycone isoflavones are in the order genistein > daidzein > glycitein, with concentrations of each compound depending on the cultivar and local environmental conditions. For example, hot and dry weather can result in low-grade crops, which lead to a reduction in overall isoflavone concentration [54]. Daidzein is the aglycone of daidzin and malonyldaidzin, genistein is the aglycone of genistin and malonylgenistin, and glycitein is the aglycone of glycitin and malonylglycitin. Replacement of the sugar residue (glycosyl group) with a hydrogen atom leads to the conversion of glycosides to aglycone compounds. Our study revealed that after $5 \mathrm{~min}$ UV-C 
treatment, the concentrations of the aglycone compounds daidzein, glycitein, and genistein were increased significantly many fold in all five soybean cultivars (Table S1).

In a previous study, $1 \mathrm{mM}$ salicylic acid applied at the full pod stage increased glycitein concentration by $81 \%$ [55]. Similarly, in another study, the total isoflavone concentration in soybean seeds was $92.7 \%$ higher than that in a control after application of $0.1 \mathrm{mM}$ salicylic acid. Daidzein and glycitein concentrations in soybean seeds were found to increase by $53.7 \%$ and $78.7 \%$, respectively, while genistein concentration only increased by $2.9 \%$ after the application of $0.5 \mathrm{mM}$ methyl jasmonate in soybean seeds compared with a control [56]. Similarly, following the application of $1 \mathrm{mM}$ ethyl acetate, glycitein concentration increased by 3.3-fold; however, daidzein and genistein concentrations only increased by $12.3 \%$ and $10.2 \%$, respectively, at the full pod stage of soybean [55]. Light illumination positively affects the callus induction in three Korean cultivars of soybean. In a study where the isoflavone synthase gene was transformed to promote higher isoflavone concentrations, the total isoflavone concentration in the callus tissues of the transformed line was three- to sixfold higher than that in the control cell line [57]. In another study, $\mathrm{NaN}_{3}$-induced soybean mutants had higher total isoflavone concentrations (on average $5 \%$ to $25 \%$ higher) than their wild-type cultivar [58]. Furthermore, many studies have demonstrated that postharvest UV-C treatment in detached leaves, vegetables and fruits increases the secondary metabolite contents and their biosynthetic enzymes [59-64].

The majority of aglycone isoflavones are in the free and conjugated forms of genistein and daidzein, which constitute $60 \%$ and $30 \%$ of the total aglycone isoflavone concentration, respectively, while the glycitein group is a minor component $(10 \%)[65,66]$. Aglycones are generated mainly from malonyl glucosides [30,52], which are possibly converted into aglycones in response to UV-C. This would explain the high aglycone concentrations in our experiment. It has also been reported that glycitein is responsive to elicitors such as salicylic acid, methyl salicylate, and ethyl acetate; aglycone concentrations were $256 \%$ higher in soybean plants following $1 \mathrm{mM}$ ethyl acetate treatment than under a control treatment. In an isoflavone synthase-transformed soybean cv. Sojin cell line, there were comparatively higher concentrations of malonyldaidzin than that of malonylgenistin, genistein, and daidzein. However, the concentrations of malonylgenistin, daidzein, and genistein were similar to those found in the non-transformed cell line of soybean [57].

UV-C irradiation can influence the photosynthetic pigments and other physiological and biochemical components of plants [3,4,16,67]. It has been found that the concentrations of carotenoids, anthocyanins, flavonoids, and proline were significantly higher following UV-C treatment compared with a control [16,63,67-71]. The pigment apigeninidin (3-deoxy anthocyanidin) accumulated in the epidermal layer of soybean cotyledons irradiated for $60 \mathrm{~min}$ with UV-C radiation. Interestingly, the authors said that this pigment was not verified in soybean species primarily, and only UV-C led to its induced accumulation. An in vitro test showed that apigeninidin had the ability to reduce lipid radicals in a dose-dependent manner and possessed antioxidant activities [51]. UV-C irradiation plays an important role in some biological processes such as cell rescue, protein fate, secondary metabolism, and transcription regulation [64]. UV-C treatment can increase the antioxidant activity in fresh cut red cabbage in storage [63,72], and can increase the trans-resveratrol concentration from 2.19 to $56.76 \mu \mathrm{g} \mathrm{g}^{-1}$ of fresh weight in Vitis amurensis cv. Tonghua-3. The increase in concentration of secondary metabolites may be linked to the transcriptional regulation of genes involved their biosynthesis and signaling [73-76]. Thus, UV-C irradiation has been directly correlated with the regulation of key biosynthetic enzymes such as stilbene synthase (STS), phenylalanine ammonia lyase, and chalcone synthase (CHS), etc.

Higher isoflavone concentrations in soybean leaves were observed in the present study after UV-C irradiation from a $30 \mathrm{~cm}$ distance. This may have been due to higher activities of the major biosynthetic enzymes such as chalcone synthase (CHS), chalcone reductase (CHR), and isoflavone synthase (IFS), since these enzymes may be significantly induced after UV elicitation [77,78]. Thus, low doses of UV-C allow the plants to partially recover to their normal physiological status and trigger the key enzymes of their metabolic pathway, ultimately leading to the production isoflavone compounds in soybean leaves. 


\section{Materials and Methods}

\subsection{Plant Materials}

Soybean seeds of five cultivars, namely, Soyoung, Daepung, Young-yang, Daewon, and Pungsan, were sown in pots containing sand and soil (1:1). Plants were grown in a greenhouse at normal conditions $\left(20 \pm 2{ }^{\circ} \mathrm{C}\right.$ temperature and 16 light/8 darkness hour photoperiod) and watered regularly. When the plants were 6 weeks old, we collected healthy and morphologically similar leaves from the same plant for further experimentation.

\subsection{Ultraviolet-C Irradiation}

For the first experiment, the leaves of each cultivar collected from the greenhouse were placed in separate vinyl zipper polybags, weighed individually, and immediately transferred to a plastic box containing a wet paper towel. Leaves were exposed to UV-C (260 nm) from $30 \mathrm{~cm}$ distance at $24{ }^{\circ} \mathrm{C}$ in the dark. The abaxial (lower) surface faced the source of light for different time periods. Further, one experimental leaf sample was placed with the adaxial (upper) surface facing the light. After UV-C exposure, the leaves were incubated in a growth chamber at $24{ }^{\circ} \mathrm{C}$ in the dark for $24 \mathrm{~h}$. The controls consisted of leaves that underwent the same treatment lacking the UV-C exposure. After incubation, the leaves were stored separately in individual vinyl zipper bags for $24 \mathrm{~h}$ in a deep freezer $\left(-80^{\circ} \mathrm{C}\right)$ until isoflavone extraction. For the second experiment, morphologically similar leaves of the cultivar Daepung were collected and exposed to UV-C radiation for three different periods of time $(5,10$, and $20 \mathrm{~min})$. As in the first experiment, leaves were then incubated and frozen for $24 \mathrm{~h}$. Similar to the first experiment, in the second experiment, the control consisted of leaves that underwent the same treatment lacking the UV-C exposure. Additionally, the leaves without UV-C irradiation as well as without incubation (termed as no incubation) were also included.

\subsection{Preparation of Plant Extracts}

The previously frozen leaf samples were ground to a powder using a mortar and pestle and $80 \%$ ethanol ( $9 \mathrm{~mL}$ ethanol for $1 \mathrm{~g}$ of leaf). The samples were then placed in $50 \mathrm{~mL}$ falcon tubes and shaken for $1 \mathrm{~h}$ at room temperature in the dark. Samples were then filtered using a nylon filter (Nylon 0.22 $\mu \mathrm{m})$, and $1.8 \mathrm{~mL}$ of filtrate was collected for LC-MS analysis.

\subsection{Quantification of Isoflavonoids by LC-MS Analysis}

The concentrations of isoflavone compounds were determined using an LC-MS system consisting of a high-performance liquid chromatography (HPLC) apparatus (model 2695; Waters, Milford, MA, USA) equipped with a pentafluorophenyl column (Luna C18 reversed phase column, $4.6 \times 150 \mathrm{~mm}$, $5 \mu \mathrm{m}$; Phenomenex, Torrance, CA, USA) and a mass spectrometer (model 3100; Waters). The conditions for HPLC were as follows: injection volume $=5 \mu \mathrm{L}$; solvent $\mathrm{A}=20 \mathrm{mM}$ ammonium acetate buffer $(\mathrm{pH}$ adjusted to 7.2); solvent $B=$ acetonitrile; and solvent program = 50:50 (A/B) to 50:50 (A/B) over 10 min at a flow rate of $0.5 \mathrm{~mL} \mathrm{~min}{ }^{-1}$. The mass spectrometry analysis conditions were as follows: $\mathrm{N}_{2}$ gas flow rate $=4 \mathrm{~L} \mathrm{~h}^{-1}$; temperature $=350{ }^{\circ} \mathrm{C}$; capillary voltage $=4 \mathrm{kV}$; cone voltage $=30 \mathrm{~V}$; ionization mode = electrospray positive; single ion recording $(\mathrm{m} / \mathrm{z})=255$ for daidzin, malonyldaidzin, and daidzein; $m / z=271$ for genistin, malonylgenistin, and genistein; and $m / z=285$ for glycitin, malonylglycitin, and glycitein.

\subsection{Statistical Analysis}

The graphs and tables were prepared using Microsoft Office Excel. All data are expressed as the mean \pm standard deviation (SD) from three independent replicates in each experiment. Statistical analysis of samples was conducted using one-way analyses of variance (ANOVAs) followed by 
Duncan's multiple range tests at a $p$-value of $<0.05$ using Statistical Analysis System (SAS version 9.4, SAS Institute Inc., Cary, NC, USA).

\section{Conclusions}

Isoflavones have a chemical structure similar to that of human estrogen. They play a significant role in a healthy diet and help in fighting disease. Soybean plants produce three groups of isoflavones, which belong to four chemical forms: aglycones (daidzein, genistein, and glycitein), $\beta$-glucosides (daidzin, genistin, and glycitin), acetylglucosides (acetyldaidzin, acetylgenistin, and acetylglycitin), and malonylglucosides (malonyldaidzin, malonylgenistin, and malonylglycitin), making a total of 12 isoflavones. In the present study, nine isoflavone compounds (all forms except acetylglucosides) were detected in soybean leaves following UV-C treatment ( $5 \mathrm{~min}$ and $30 \mathrm{~cm}$ from the leaf surface). The large variation in isoflavone concentrations among different cultivars suggested that cultivar selection is a key parameter for optimizing the isoflavone concentration. Among all isoflavones, the most beneficial are the aglycosides, especially genistein and daidzein, which are important for maintaining good bone density, and their concentrations were significantly higher after UV elicitation. In the current study, concentrations of aglycone isoflavones in the cultivar Soyoung after $5 \mathrm{~min}$ UV-C irradiation followed the order genistein $>$ daidzein $>$ glycitein, but in all other cultivars, it followed the order daidzein $>$ genistein $>$ glycitein.

On the basis of the results, the cultivar Daepung was selected as the most effective cultivar for isoflavone induction through UV-C irradiation. Then, the optimal irradiation length for aglycoside and glycoside isoflavone compound production was determined. We found that aglycoside compound concentrations were the highest after 20 min UV-C irradiation, while glycoside compound concentrations were the highest after $5 \mathrm{~min}$ of the adaxial surface facing the UV-C source. Overall, this study shows that both the cultivar and length of UV-C exposure influence isoflavone concentrations in soybean plants. However, the exact mechanism of isoflavone induction through UV-C elicitation is still unexplored and requires further experimental validation.

Supplementary Materials: The following are available online at http://www.mdpi.com/2223-7747/9/8/1043/s1, Table S1: Effect of UV-C ( $260 \mathrm{~nm}, 5 \mathrm{~min})$ irradiation on isoflavone concentrations in different cultivars of Glycine max. Table S2: Isoflavone concentrations in Glycine max (cv. Daepung) after UV-C (260 nm) irradiation.

Author Contributions: K.-H.B. conceived and designed the experiments. K.B.K. and A.K.M. performed the experiment. S.-J.C. and K.-H.B. analyzed data and wrote the paper. All authors have read and agreed to the published version of the manuscript.

Funding: This study was supported by the Basic Science Research Program through the National Research Foundation of Korea (NRF) funded by the Ministry of Education (NRF-2019R1F1A1052625).

Acknowledgments: The authors are grateful to the research fund from NRF (NRF-2019R1F1A1052625).

Conflicts of Interest: The authors declare no conflict of interest.

\section{References}

1. Sun, B.; Ribes, A.M.; Leandro, M.C.; Belchior, A.P.; Spranger, M.I. Stilbenes: Quantitative extraction from grape skins, contribution of grape solids to wine and variation during wine maturation. Anal. Chim. Acta 2006, 563, 382-390. [CrossRef]

2. Mao, B.; Yin, H.; Wang, Y.; Zhao, T.-H.; Tian, R.-R.; Wang, W.; Ye, J.-S. Combined effects of $\mathrm{O}_{3}$ and UV radiation on secondary metabolites and endogenous hormones of soybean leaves. PLoS ONE 2017, 12, e0183147. [CrossRef] [PubMed]

3. Ullah, M.A.; Tungmunnithum, D.; Garros, L.; Drouet, S.; Hano, C.; Abbasi, B.H. Effect of ultraviolet-C radiation and melatonin stress on biosynthesis of antioxidant and antidiabetic metabolites produced in in vitro callus cultures of Lepidium sativum L. Int. J. Mol. Sci. 2019, 20, 1787. [CrossRef] [PubMed]

4. Anjum, S.; Abbasi, B.H.; Doussot, J.; Favre-Réguillon, A.; Hano, C. Effects of photoperiod regimes and ultraviolet-C radiations on biosynthesis of industrially important lignans and neolignans in cell cultures of Linum usitatissimum L. (Flax). J. Photochem. Photobiol. B Biol. 2017, 167, 216-227. [CrossRef] 
5. Loyall, L.; Uchida, K.; Braun, S.; Furuya, M.; Frohnmeyer, H. Glutathione and a UV light-induced glutathione S-transferase are involved in signaling to chalcone synthase in cell cultures. Plant Cell 2000, 12, 1939-1950.

6. Katerova, Z.; Ivanov, S.; Mapelli, S.; Alexieva, V. Phenols, proline and low-molecular thiol levels in pea (Pisum sativum) plants respond differently toward prolonged exposure to ultraviolet-B and ultraviolet-C radiations. Acta Physiol. Plant 2009, 31, 111-117. [CrossRef]

7. Katerova, Z.; Todorova, D. Effect of enhanced UV-C irradiation on the growth, malondialdehyde, hydrogen peroxide, free proline, polyamines, IAA and IAA-oxidase activity in pea plants (Pisum sativum L.). Comptes Rendus L'Academie Bulg. Sci. 2011, 64, 1555-1562.

8. Rai, R.; Meena, R.P.; Smita, S.S.; Shukla, A.; Rai, S.K.; Pandey-Rai, S. UV-B and UV-C pre-treatments induce physiological changes and artemisinin biosynthesis in Artemisia annua L.-An antimalarial plant. J. Photochem. Photobiol. B Biol. 2011, 105, 216-225. [CrossRef]

9. Alexieva, V.; Sergiev, I.; Mapelli, S.; Karanov, E. The effect of drought and ultraviolet radiation on growth and stress markers in pea and wheat. Plant Cell Environ. 2001, 24, 1337-1344. [CrossRef]

10. Frohnmeyer, H.; Staiger, D. Ultraviolet-B radiation-mediated responses in plants. Balancing damage and protection. Plant Physiol. 2003, 133, 1420-1428. [CrossRef]

11. Zacchini, M.; De Agazio, M. Spread of oxidative damage and antioxidative response through cell layers of tobacco callus after UV-C treatment. Plant Physiol. Biochem. 2004, 42, 445-450. [CrossRef] [PubMed]

12. Procházková, D.; Wilhelmová, N. The capacity of antioxidant protection during modulated ageing of bean (Phaseolus vulgaris L.) cotyledons. 1. The antioxidant enzyme activities. Cell Biochem. Funct. 2007, 25, 87-95. [CrossRef] [PubMed]

13. Takeuchi, Y.; Inoue, T.; Takemura, K.; Hada, M.; Takahashi, S.; Ioki, M.; Nakajima, N.; Kondo, N. Induction and inhibition of cyclobutane pyrimidine dimer photolyase in etiolated cucumber (Cucumis sativus) cotyledons after ultraviolet irradiation depends on wavelength. J. Plant Res. 2007, 120, 365-374. [CrossRef] [PubMed]

14. Danon, A.; Gallois, P. UV-C radiation induces apoptotic-like changes in Arabidopsis thaliana. FEBS Lett. 1998, 437, 131-136. [CrossRef]

15. Sharma, R.; Sharma, A.; Shono, T.; Takasugi, M.; Shirata, A.; Fujimura, T.; Machii, H. Mulberry moracins: Scavengers of UV stress-generated free radicals. Biosci. Biotechnol. Biochem. 2001, 65, 1402-1405. [CrossRef]

16. Esua, O.J.; Chin, N.L.; Yusof, Y.A.; Sukor, R. Effects of simultaneous UV-C radiation and ultrasonic energy postharvest treatment on bioactive compounds and antioxidant activity of tomatoes during storage. Food Chem. 2019, 270, 113-122. [CrossRef]

17. Ballaré, C.L.; Stapleton, A.E.; Yanovsky, M.J.; Scopel, A.L. Solar ultraviolet-B radiation affects seedling emergence, DNA integrity, plant morphology, growth rate, and attractiveness to herbivore insects in Datura ferox. Plant Physiol. 1996, 112, 161-170. [CrossRef]

18. Mishra, A.K.; Choi, S.J.; Baek, K.H. Application of ultraviolet c irradiation for the increased production of secondary metabolites in plants. J. Anim. Plant Sci. 2020, 30, 1082-1091.

19. Ghasemi, S.; Kumleh, H.H.; Kordrostami, M. Changes in the expression of some genes involved in the biosynthesis of secondary metabolites in Cuminum cyminum L. under UV stress. Protoplasma 2019, 256, 279-290. [CrossRef]

20. Edreva, A.; Velikova, V.; Tsonev, T.; Dagnon, S.; Gürel, A.; Aktaş, L.; Gesheva, E. Stress-protective role of secondary metabolites: Diversity of functions and mechanisms. Gen. Appl. Plant Physiol. 2008, 34, 67-78.

21. Pichersky, E.; Gang, D.R. Genetics and biochemistry of secondary metabolites in plants: An evolutionary perspective. Trends Plant Sci. 2000, 5, 439-445. [CrossRef]

22. Brössner, C.; Petritsch, K.; Fink, K.; Auprich, M.; Madersbacher, S.; Adlercreutz, H.; Rehak, P.; Petritsch, P. Phytoestrogen tissue levels in benign prostatic hyperplasia and prostate cancer and their association with prostatic diseases. Urology 2004, 64, 707-711. [CrossRef] [PubMed]

23. Heinonen, S.M.; Hoikkala, A.; Wähälä, K.; Adlercreutz, H. Metabolism of the soy isoflavones daidzein, genistein and glycitein in human subjects. Identification of new metabolites having an intact isoflavonoid skeleton. J. Steroid Biochem. Mol. Biol. 2003, 87, 285-299. [CrossRef] [PubMed]

24. Zhang, E.J.; Ka, M.N.; Luo, K.Q. Extraction and purification of isoflavones from soybeans and characterization of their estrogenic activities. J. Agric. Food Chem. 2007, 55, 6940-6950. [CrossRef] [PubMed]

25. Kř́žová, L.; Dadáková, K.; Kašparovská, J.; Kašparovský, T. Isoflavones. Molecules 2019, 24, 1076. [CrossRef] [PubMed] 
26. Breinholt, V.; Larsen, J.C. Detection of weak estrogenic flavonoids using a recombinant yeast strain and a modified $\mathrm{MCF}_{7}$ cell proliferation assay. Chem. Res. Toxicol. 1998, 11, 622-629. [CrossRef] [PubMed]

27. Collins, B.M.; McLachlan, J.A.; Arnold, S.F. The estrogenic and antiestrogenic activities of phytochemicals with the human estrogen receptor expressed in yeast. Steroids 1997, 62, 365-372. [CrossRef]

28. Peterson, J.; Dwyer, J. Flavonoids: Dietary occurrence and biochemical activity. Nutr. Res. 1998, 18, $1995-2018$. [CrossRef]

29. Wollenweber, E.; Dietz, V.H. Occurrence and distribution of free flavonoid aglycones in plants. Phytochemistry 1981, 20, 869-932. [CrossRef]

30. Kudou, S.; Fleury, Y.; Welti, D.; Magnolato, D.; Uchida, T.; Kitamura, K.; Okubo, K. Malonyl isoflavone glycosides in soybean seeds (Glycine max Merrill). Agric. Biol. Chem. 1991, 55, 2227-2233. [CrossRef]

31. Goetzl, M.A.; Vanveldhuizen, P.J.; Thrasher, J.B. Effects of soy phytoestrogens on the prostate. Prostate Cancer Prostatic Dis. 2007, 10, 216-223. [CrossRef] [PubMed]

32. Franke, A.A.; Custer, L.J.; Cerna, C.M.; Narala, K.K. Quantitation of phytoestrogens in legumes by HPLC. J. Agric. Food Chem. 1994, 42, 1905-1913. [CrossRef]

33. Lee, K.H.; Xiao, Z. Lignans in treatment of cancer and other diseases. Phytochem. Rev. 2003, 2, 341-362. [CrossRef]

34. Butsayawarapat, P.; Juntawong, P.; Khamsuk, O.; Somta, P. Comparative transcriptome analysis of waterlogging-sensitive and tolerant zombi pea (Vigna Vexillata) reveals energy conservation and root plasticity controlling waterlogging tolerance. Plants 2019, 8, 264. [CrossRef]

35. Graham, T.L. Biosynthesis and distribution of phytoestrogens and their roles in plant defense, signal transduction, and cell-to-cell signaling. J. Med. Food 1999, 2, 93-97. [CrossRef]

36. Reinli, K.; Block, G. Phytoestrogen content of foods-A compendium of literature values. Nutr. Cancer 1996, 26, 123-148. [CrossRef] [PubMed]

37. Mazur, W.M.; Duke, J.A.; Wähälä, K.; Rasku, S.; Adlercreutz, H. Isoflavonoids and lignans in legumes: Nutritional and health aspects in humans. J. Nutr. Biochem. 1998, 9, 193-200. [CrossRef]

38. Tham, D.M.; Gardner, C.D.; Haskell, W.L. Potential health benefits of dietary phytoestrogens: A review of the clinical, epidemiological, and mechanistic evidence. J. Clin. Endocrinol. Metab. 2011, 83, 2223-2235. [CrossRef]

39. Barnes, S. The chemopreventive properties of soy isoflavonoids in animal models of breast cancer. Breast Cancer Res. Treat. 1997, 46, 169-179. [CrossRef]

40. Messina, M.; Barnes, S. The role of soy products in reducing risk of cancer. J. Natl. Cancer Inst. 1991, 83, 541-546. [CrossRef]

41. Adlercreutz, H. Phytoestrogens: Epidemiology and a possible role in cancer protection. Environ. Health Perspect. 1995, 103, 103-112. [PubMed]

42. Adlercreutz, H. Phyto-oestrogens and cancer. Lancet Oncol. 2002, 3, 364-373. [CrossRef]

43. Strauss, L.; Santti, R.; Saarinen, N.; Streng, T.; Joshi, S.; Makela, S. Dietary phytoestrogens and their role in hormonally dependent disease. Toxicol. Lett. 1998, 102-103, 349-354. [CrossRef]

44. Zhou, J.R.; Gugger, E.T.; Tanaka, T.; Guo, Y.; Blackburn, G.L.; Clinton, S.K. Soybean phytochemicals inhibit the growth of transplantable human prostate carcinoma and tumor angiogenesis in mice. J. Nutr. 1999, 129, 1628-1635. [CrossRef]

45. Swanson, M.; Stoll, M.; Schapaugh, W.; Takemoto, L. Isoflavone content of Kansas soybeans. Am. J. Undergrad. Res. 2004, 2, 27-32. [CrossRef]

46. Rizzo, G.; Baroni, L. Soy, soy foods and their role in vegetarian diets. Nutrients 2018, 10, 43. [CrossRef]

47. Bou, S.M.; Shih, F.; Shih, B.Y.; Daigle, K.W.; Carter-Wientjes, C.H.; Cleveland, T.E. Effect of biotic elicitors on enrichment of antioxidant properties and induced isoflavones in soybean. J. Food Sci. 2008, 73, 43-49. [CrossRef]

48. Cantos, E.; Garcia-Viguera, C.; De Pascual-Teresa, S.; Tomas-Barberan, F.A. Effect of postharvest ultraviolet irradiation on resveratrol and other phenolics of cv. Napoleon table grapes. J. Agric. Food Chem. 2000, 48, 4606-4612. [CrossRef]

49. Cetin, E.S. Induction of secondary metabolite production by UV-C radiation in Vitis vinifera L. Öküzgözü callus cultures. Biol. Res. 2014, 47, 1-7. [CrossRef] 
50. Guerrero, R.F.; Puertas, B.; Fernández, M.I.; Palma, M.; Cantos-Villar, E. Induction of stilbenes in grapes by UV-C: Comparison of different subspecies of Vitis. Innov. Food Sci. Emerg. Technol. 2010, 11, 231-238. [CrossRef]

51. Katerova, Z.; Todorova, D.; Tasheva, K.; Sergiev, I. Influence of ultraviolet radiation on plant secondary metabolite production. Genet. Plant Physiol. 2012, 2, 113-144.

52. De Rijke, E.; Zafra-Gómez, A.; Ariese, F.; Brinkman, U.A.T.; Gooijer, C. Determination of isoflavone glucoside malonates in Trifolium pratense L. (red clover) extracts: Quantification and stability studies. J. Chromatogr. A 2001, 932, 55-64. [CrossRef]

53. Tumova, L.; Tuma, J. The effect of UV light on isoflavonoid production in Genista tinctoria culture in vitro. Acta Physiol. Plant 2011, 33, 635-640. [CrossRef]

54. Lozovaya, V.V.; Lygin, A.V.; Ulanov, A.V.; Nelson, R.L.; Dayde, J.; Widholm, J.M. Effect of temperature and soil moisture status during seed development on soybean seed isoflavone concentration and composition. Crop Sci. 2005, 45, 1934-1940. [CrossRef]

55. Zhang, B.; Hettiarachchy, N.; Chen, P.; Horax, R.; Cornelious, B.; Zhu, D. Influence of the application of three different elicitors on soybean plants on the concentrations of several isoflavones in soybean seeds. J. Agric. Food Chem. 2006, 54, 5548-5554. [CrossRef] [PubMed]

56. Saini, R.K.; Devi, M.K.A.; Giridhar, P.; Gokare, R.; Bot, A. Augmentation of major isoflavones in Glycine max L. through the elicitor-mediated approach. Acta Bot. Croat. 2013, 72, 311-322. [CrossRef]

57. Jiang, N.; Jeon, E.H.; Pak, J.H.; Ha, T.J.; Baek, I.Y.; Jung, W.S.; Lee, J.H.; Kim, D.H.; Choi, H.K.; Cui, Z.; et al. Increase of isoflavones in soybean callus by Agrobacterium-mediated transformation. Plant Biotechnol. Rep. 2010, 4, 253-260. [CrossRef]

58. Jeng, T.L.; Shih, Y.J.; Wu, M.T.; Wang, C.S.; Sung, J.M. Evaluations and selections for high isoflavone black soybean mutants induced by $\mathrm{NaN}_{3}$ treatment. Am. J. Plant Sci. 2013, 4, 35-40. [CrossRef]

59. Cantos, E.; Espín, J.C.; Tomás-Barberán, F.A. Postharvest induction modeling method using UV irradiation pulses for obtaining resveratrol-enriched table grapes: A new "Functional" fruit? J. Agric. Food Chem. 2001, 49, 5052-5058. [CrossRef]

60. Chen, C.; Hu, W.; He, Y.; Jiang, A.; Zhang, R. Effect of citric acid combined with UV-C on the quality of fresh-cut apples. Postharvest Biol. Technol. 2016, 111, 126-131. [CrossRef]

61. Jagadeesh, S.L.; Charles, M.T.; Gariepy, Y.; Goyette, B.; Raghavan, G.S.V.; Vigneault, C. Influence of postharvest UV-C hormesis on the bioactive components of tomato during post-treatment handling. Food Bioprocess Technol. 2011, 4, 1463-1472. [CrossRef]

62. Lu, Y.; Zhang, J.; Wang, X.; Lin, Q.; Liu, W.; Xie, X.; Wang, Z.; Guan, W. Effects of UV-C irradiation on the physiological and antioxidant responses of button mushrooms (Agaricus bisporus) during storage. Int. J. Food Sci. Technol. 2016, 51, 1502-1508. [CrossRef]

63. Wang, D.; Chen, L.; Ma, Y.; Zhang, M.; Zhao, Y.; Zhao, X. Effect of UV-C treatment on the quality of fresh-cut lotus (Nelumbo nucifera Gaertn.) root. Food Chem. 2019, 278, 659-664. [CrossRef] [PubMed]

64. Xi, H.; Ma, L.; Liu, G.; Wang, N.; Wang, J.; Wang, L.; Dai, Z.; Li, S.; Wang, L. Transcriptomic analysis of grape (Vitis vinifera L.) leaves after exposure to ultraviolet C irradiation. PLoS ONE 2014, 9, e113772. [CrossRef] [PubMed]

65. Barnes, S. The biochemistry, chemistry and physiology of the isoflavones in soybeans and their food products. Lymphat. Res. Biol. 2010, 8, 89-98. [CrossRef]

66. Collison, M.W. Determination of total soy isoflavones in dietary supplements, supplement ingredients, and soy foods by high-performance liquid chromatography with ultraviolet detection: Collaborative study. J. AOAC Int. 2008, 91, 489-500. [CrossRef]

67. Mahdavian, K.; Kalantari, K.M.; Ghorbanli, M.; Torkzade, M. The effects of salicylic acid on pigment contents in ultraviolet radiation stressed pepper plants. Biol. Plant. 2008, 52, 170-172. [CrossRef]

68. Balouchi, H.R.; Sanavy, S.A.M.M.; Emam, Y.; Dolatabadian, A. UV radiation, elevated $\mathrm{CO}_{2}$ and water stress effect on growth and photosynthetic characteristics in durum wheat. Plant Soil Environ. 2009, 55, 443-453. [CrossRef]

69. Wang, J.F.; Ma, L.; Xi, H.F.; Wang, L.J.; Li, S.H. Resveratrol synthesis under natural conditions and after UV-C irradiation in berry skin is associated with berry development stages in "Beihong" (V. vinifera $\times$ V. amurensis). Food Chem. 2015, 168, 430-438. [CrossRef] 
70. Bravo, S.; García-Alonso, J.; Martín-Pozuelo, G.; Gómez, V.; Santaella, M.; Navarro-González, I.; Periago, M.J. The influence of post-harvest UV-C hormesis on lycopene, $\beta$-carotene, and phenolic content and antioxidant activity of breaker tomatoes. Food Res. Int. 2012, 49, 296-302. [CrossRef]

71. Wang, C.Y.; Chen, C.T.; Wang, S.Y. Changes of flavonoid content and antioxidant capacity in blueberries after illumination with UV-C. Food Chem. 2009, 117, 426-431. [CrossRef]

72. Wu, J.; Liu, W.; Yuan, L.; Guan, W.-Q.; Brennan, C.S.; Zhang, Y.-Y.; Zhang, J.; Wang, Z.-D. The influence of postharvest UV-C treatment on anthocyanin biosynthesis in fresh-cut red cabbage. Sci. Rep. 2017, 7, 5232. [CrossRef]

73. Yin, X.; Singer, S.D.; Qiao, H.; Liu, Y.; Jiao, C.; Wang, H.; Li, Z.; Fei, Z.; Wang, Y.; Fan, C.; et al. Insights into the mechanisms underlying ultraviolet-C induced resveratrol metabolism in grapevine ( $V$. amurensis Rupr.) cv. "Tonghua-3". Front. Plant Sci. 2016, 7, 503.

74. Sheng, K.; Shui, S.; Yan, L.; Liu, C.; Zheng, L. Effect of postharvest UV-B or UV-C irradiation on phenolic compounds and their transcription of phenolic biosynthetic genes of table grapes. J. Food Sci. Technol. 2018, 55, 3292-3302. [CrossRef]

75. Takayanagi, T.; Okuda, T.; Mine, Y.; Yokotsuka, K. Induction of resveratrol biosynthesis in skins of three grape cultivars by ultraviolet irradiation. J. Jpn. Soc. Hort. Sci. 2004, 73, 193-199. [CrossRef]

76. Wang, W.; Tang, K.; Yang, H.R.; Wen, P.F.; Zhang, P.; Wang, H.L.; Huang, W.D. Distribution of resveratrol and stilbene synthase in young grape plants (Vitis vinifera L. cv. Cabernet Sauvignon) and the effect of UV-C on its accumulation. Plant Physiol. Biochem. 2010, 48, 142-152. [CrossRef] [PubMed]

77. Jung, W.; Yu, O.; Lau, S.M.; O’Keefe, D.P.; Odell, J.; Fader, G.; McGonigle, B. Identification and expression of isoflavone synthase, the key enzyme for biosynthesis of isoflavones in legumes. Nat. Biotechnol. 2000, 18, 208-212. [CrossRef]

78. Sugiyama, A.; Yamazaki, Y.; Hamamoto, S.; Takase, H.; Yazaki, K. Synthesis and secretion of isoflavones by field-grown soybean. Plant Cell Physiol. 2017, 58, 1594-1600. [CrossRef] [PubMed]

(C) 2020 by the authors. Licensee MDPI, Basel, Switzerland. This article is an open access article distributed under the terms and conditions of the Creative Commons Attribution (CC BY) license (http://creativecommons.org/licenses/by/4.0/). 